\title{
Adhesion strategy and early bond strengths of glass-fiber posts luted into root canals
}

\section{André Luis Faria-e-Silva(a) Adriano Augusto Melo Mendonça(a) Rosa Maria Viana de Bragança Garcez $^{(a)}$}

Aline da Silva de Oliveira ${ }^{(b)}$ Andressa Goicochea Moreira ${ }^{(b)}$ Rafael Ratto de Moraes ${ }^{(b)}$

(a) Department of Dentistry, School of Dentistry, Federal Univ of Sergipe, Aracaju, SE, Brazil.

(b) Department of Restorative Dentistry, School of Dentistry, Federal Univ of Pelotas, Pelotas, RS, Brazil.
Declaration of Interests: The authors certify that they have no commercial or associative interest that represents a conflict of interest in connection with the manuscript.

Corresponding Author: André Luis Faria-e-Silva

E-mail: fariaesilva.andre@gmail.com

Submitted: Mar 17, 2012

Accepted for publication: Jun 04, 2012 Last revision: Jun 13, 2012

\begin{abstract}
This study investigated the effect of coinitiator solutions and self-adhesive resin cement on the early retention of glass-fiber posts. Cylindrical glass-fiber posts were luted into 40 incisor roots with different adhesion strategies $(n=10)$ : SB2, Single Bond $2+$ conventional resin cement (RelyX ARC); AP, Scotchbond Multipurpose Plus (SBMP) activator + primer + ARC; APC, SBMP activator + primer + catalyst + ARC; and UNI, self-adhesive cement (RelyX Unicem). Pull-out bond strength results at $10 \mathrm{~min}$ after cementation showed $\mathrm{APC}>\mathrm{UNI}>\mathrm{SB} 2=\mathrm{AP}$ $(P<0.05)$. The adhesion strategy significantly affected early bonding to root canals.
\end{abstract}

Descriptors: Dental Bonding; Polymerization; Post and Core Technique; Resin Cements.

\section{Introduction}

As a result of low light access during post-cementation, dual-cure resin cements (RCs) primarily rely on self-curing, ${ }^{1}$ a slow setting mechanism resulting in low conversion in the first few minutes following cementation. Thus, some manufacturers have developed primer and adhesive solutions containing coinitiators to enhance the polymerization rate of $\mathrm{RCs}^{2}$ and to improve the early retention of fiber posts luted into root canals. However, processes involving more cementation steps are in conflict with the trend towards simplifying adhesive techniques. ${ }^{3}$ In this context, self-adhesive RCs are gaining popularity.

Bond strength evaluations of fiber posts bonded to root canals are usually performed at least $24 \mathrm{~h}$ after the luting procedures. ${ }^{3,4}$ Clinically, however, luted posts might be subject to stress immediately after completion of the core/restoration assembly. Thus, the aim of this study was to evaluate the effect of the adhesion strategy (using coinitiators or a selfadhesive RC) on the early retention of fiber posts luted to root canals, by testing the pull-out bond strength at $10 \mathrm{~min}$ after cementation.

\section{Methodology}

Forty bovine incisor roots were sectioned with a low-speed diamond saw to obtain a $16-\mathrm{mm}$ height. For endodontic treatment, a step-back preparation technique was used with stainless-steel K-files and GatesGlidden drills \#2 to \#4. All enlargement procedures were followed by irrigation with $2.5 \% \mathrm{NaOCl}$ solution. The root canals were obturated 
Table 1 - Description of the tested adhesion strategies.

\begin{tabular}{|c|c|}
\hline Group & Application protocol \\
\hline SB2 & $\begin{array}{l}\text { 1. Etch with } 37 \% \text { phosphoric acid for } 15 \mathrm{~s} \text {, rinse with air-water spray, and remove excess } \\
\text { water with absorbent paper cones } \\
\text { 2. Apply the bonding agent Single Bond } 2 \text { ( } 3 \mathrm{M} \text { ESPE, St. Paul, USA), and air-dry for } 5 \mathrm{~s} \\
\text { 3. Light-activate the adhesive for } 20 \mathrm{~s} \text { with a light-emitting diode (LED) unit at } \\
600-\mathrm{mw} / \mathrm{cm}^{2} \text { (Radii; SDI, Bayswater Victoria, Australia) } \\
\text { 4. Insert the post and dual-cure resin cement RelyX ARC ( } 3 \mathrm{M} \mathrm{ESPE),} \mathrm{and} \mathrm{light-activate} \\
\text { for } 40 \mathrm{~s}\end{array}$ \\
\hline $\mathrm{AP}$ & $\begin{array}{l}\text { 1. Perform acid-etching, rinsing, and removal of excess water } \\
\text { 2. Apply the Scotchbond Multipurpose Plus (SBMP) activator ( } 3 M \text { ESPE), and air-dry } \\
\text { for } 5 \mathrm{~s} \\
\text { 3. Apply the SBMP primer, and air-dry for } 5 \mathrm{~s} \\
\text { 4. Insert the post with RelyX ARC, and perform light-activation for } 40 \mathrm{~s}\end{array}$ \\
\hline APC & $\begin{array}{l}\text { 1. Perform acid-etching, rinsing, and removal of excess water } \\
\text { 2. Apply the SBMP activator, and air-dry } \\
\text { 3. Apply the SBMP primer, and air-dry } \\
\text { 4. Apply the SBMP catalyst, and air-dry } \\
\text { 5. Insert the post with RelyX ARC, and perform light-activation }\end{array}$ \\
\hline UNI & $\begin{array}{l}\text { 1. Apply } 2.5 \% \mathrm{NaOCl} \text { solution for } 5 \mathrm{~s} \text {, rinse with air-water spray, and remove excess } \\
\text { water with absorbent paper cones } \\
\text { 2. Insert the post with the dual-cure self-adhesive resin cement RelyX Unicem clicker, } \\
\text { and perform light-activation }\end{array}$ \\
\hline
\end{tabular}

with gutta-percha cones by the lateral condensation technique with Sealer-26 resin sealer (Dentsply Caulk, Milford, USA). After endodontic treatment, post spaces (length: $9 \mathrm{~mm}$ ) were prepared with \#5 Largo drills. The roots were embedded in polystyrene resin for positioning the specimens during the test. Parallelism between roots and posts was determined with a parallel meter.

The specimens were randomly assigned to 4 groups $(n=10)$ according to the adhesion strategy tested (Table 1). After cementation of the cylindrical glass-fiber posts, the specimens were stored in distilled water at $37^{\circ} \mathrm{C}$ for $10 \mathrm{~min}$. The bond strength was tested on a mechanical testing machine by applying a pull-out load parallel to the post/tooth long axis at a crosshead speed of $0.5 \mathrm{~mm} / \mathrm{min}$. The force required to dislodge each post was recorded. Data were analyzed by ANOVA and Student-NewmanKeuls' tests $(P<0.05)$.

\section{Results}

Significant differences (power of test $=1$ ) were observed between groups (Figure 1). APC showed the highest bond strength $(P \leq 0.006)$ followed by UNI; AP and SB2 had similar bond strengths $(P=0.493)$.

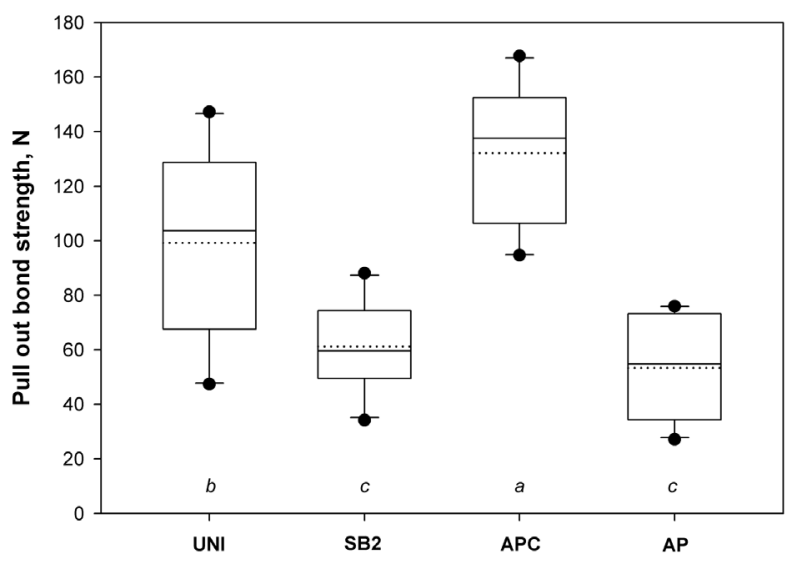

Figure 1 - Box-whisker plots for bond strength. Horizontal solid and dotted lines are medians and means, respectively. Significant differences between groups are indicated by distinct letters.

\section{Discussion}

Post retention is related to bonding to the root dentin and post friction on the canal walls, ${ }^{5}$ although both depend on proper RC polymerization. ${ }^{6}$ The observed low bond strength of SB2 was likely due to the acidic character of the adhesive reacting with the amine coinitiator of the RC, which reduced its polymerization rate. ${ }^{7}$ For AP, the combined use of primer and activator and the absence of an acidic 
character could have improved its polymerization rate. The activator contains a sulfinic acid salt that reacts with the polyalkenoic acid copolymer of the primer to generate free radicals. ${ }^{2,8}$ However, the absence of a bonding agent layer may explain the compromised post retention in AP.

In APC, the addition of a catalyst containing benzoyl peroxide increased the bond strength. Because benzoyl peroxide is responsible for the selfcure mechanism in dual-cured RCs, application of the catalyst likely improved the early cement polymerization, generating higher bond strength even without a bonding agent layer. The intermediate values of UNI can be explained by its lower early conversion. Self-adhesive RCs bond to dentin by a chelating reaction of the phosphate methacrylates with hydroxyapatite. ${ }^{9}$ However, the early bonding of selfadhesive RCs is affected by their slower polymerization compared with conventional RCs, especially in the self-cure mode. ${ }^{10}$ This slower cure is due to the presence of acidic species in self-adhesive RCs. ${ }^{10}$

\section{References}

1. Faria e Silva AL, Arias VG, Soares LE, Martin AA, Martins LR. Influence of fiber-post translucency on the degree of conversion of a dual-cured resin cement. J Endod 2007 Mar;33(3):303-5.

2. Faria-e-Silva AL, Moraes RR, Ogliari FA, Piva E, Martins LR. Panavia F: the role of primer. J Oral Sci. 2009 Jun;51(2):255-9.

3. Amaral M, Rippe MP, Bergoli CD, Monaco C, Valandro LF. Multi-step adhesive cementation versus one-step adhesive cementation: Push-out bond strength between fiber post and root dentin before and after mechanical cycling. Gen Dent. 2011 Sep;59(5):e185-91.

4. Bergoli CD, Amaral M, Druck CC, Valandro LF. Evaluation of four cementation strategies on the push-out bond strength between fiber post and root dentin. Gen Dent. 2011 Nov;59(6):498-502.

5. Goracci C, Fabianelli A, Sadek FT, Papacchini F, Tay FR, Ferrari M. The contribution of friction to the dislocation resistance of bonded fiber posts. J Endod. 2005 Aug;31(8):608-12.

6. Zhang L, Magni E, Radovic I, Wang YJ, Chen JH, Ferrari M. Effect of curing modes of dual-curing luting systems and root
The present study shows the impact of improving the early RC polymerization on post retention in the first few minutes after cementation. The quantity of self-polymerization promoters used in dual-cured RCs strongly affects their polymerization potential inside root canals. A high content of self-cure promoters leads to more effective polymerization in the absence of light (e.g., in the apical root third) and a higher polymerization rate. However, it also reduces the cement working time, ${ }^{11}$ which could impair the luting procedures. Thus, the addition of coinitiators in the bonding solution, as demonstrated here, is an efficient strategy to increase the polymerization rate of RCs without reducing their working time. This approach is important for the early bonding of posts and might improve the long-term post retention.

\section{Conclusion}

The adhesion strategy significantly affected the early bonding to root canals, and the use of coinitiator solutions improved the fiber post retention.

regions on retention of translucent fiber posts in root canals. J Adhes Dent. 2008 Jun;10(3):219-6.

7. Tay FR, Suh BI, Pashley DH, Prati C, Chuang SF, Li F. Factors contributing to the incompatibility between simplified-step adhesives and self-cured or dual-cured composites. Part II. Single-bottle, total-etch adhesive. J Adhes Dent. 2003 Summer;5(2):91-105.

8. Kwon TY, Bagheri R, Kim YK, Kim KH, Burrow MF. Cure mechanism in materials for use in esthetic dentistry. J Investig Clin Dent. 2012 Feb;3(1):3-16.

9. Ferracane JL, Stansbury JW, Burke FJ. Self-adhesive resin cements - chemistry, properties and clinical considerations. J Oral Rehabil. 2011 Apr;38(4):295-314.

10. Moraes RR, Boscato N, Jardim PS, Schneider LF. Dual and self-curing potential of self-adhesive resin cements as thin films. Oper Dent. 2011 Nov-Dec;36(6):635-42.

11. Oliveira M, César P, Giannini M, Rueggeberg F, Rodrigues J, Arrais C. Effect of temperature on the degree of conversion and working time of dual-cured resin cements exposed to different curing conditions. Oper Dent. 2012. DOI:10.2341/11 198. 